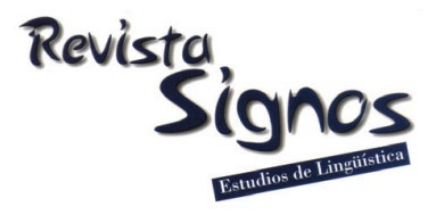

\title{
The use of poetry for EFL: Exploring the beliefs of primary school trainees
}

\author{
La poesía como herramienta en la enseñanza del inglés como \\ lengua extranjera: Las percepciones de futuros maestros de \\ educación primaria
}

\section{Mora \\ UNIVERSIDAD DE MURCIA \\ ESPAÑA \\ paferez@um.es}

Pedro Antonio Férez

\author{
Yvette Coyle \\ UNIVERSIDAD DE MURCIA \\ ESPAÑA \\ ycoyle@um.es
}

\author{
Antonio Maurandi \\ López \\ UNIVERSIDAD DE MURCIA \\ ESPAÑA \\ amaurandi@um.es
}

Recibido: 30-VIII-2017 / Aceptado: 03-V-2019
DOI: 10.4067/S0718-09342020000100056

\begin{abstract}
This study explores the perceptions of primary EFL (English as a foreign language) trainee teachers on the potential of poetry as an instrument to enhance their knowledge of English. The aim was to determine whether or not learners' opinions coincided with theoretical principles established by scholars in favour of using literature in EFL classrooms. An 18-item questionnaire was distributed to 270 trainees to obtain quantitative and qualitative data on alleged linguistic, motivational and intercultural benefits. The results confirm that trainees believe poetry-based English lessons to be more useful for developing language skills, pronunciation, grammatical and lexical knowledge than for intercultural or motivational gains. The present study contributes to the academic expansion of the field in two main ways: i) by providing evidence which empirically tests the predominantly theoretical drive of work available to date; and ii) by offering a systematic and holistic exploration of the potential advantages of poetry which goes beyond the methodologically inconsistent and fragmentary views offered by existing research.
\end{abstract}

Key Words: Poetry, EFL, motivation, perceptions, interculturality. 


\section{Resumen}

Este estudio explora la percepción de 270 estudiantes de Grado en Educación Primaria en relación al potencial de la poesía como herramienta para la enseñanza del inglés como lengua extranjera. El objetivo principal consiste en determinar si las opiniones de estos alumnos corroboran las bondades que la crítica especializada ha establecido teóricamente en este sentido. A los discentes se les dio a completar un cuestionario formado por 18 ítems con el fin de obtener datos tanto cualitativos como cuantitativos acerca de las supuestas ventajas lingüísticas, interculturales y relacionadas con la motivación que podría llevar aparejado orquestar la enseñanza del inglés como lengua extranjera desde la poesía. Los resultados confirman que los estudiantes consideran que la poesía es más útil para adquirir conocimiento lingüístico que para incrementar la motivación o el aprendizaje de aspectos interculturales. El presente estudio contribuye a la expansión de este campo de conocimiento en dos sentidos: i) demuestra empíricamente la validez de las ventajas establecidas desde la crítica teórica; y ii) ofrece una exploración sistemática y holística de las posibles ventajas de la poesía, hecho este bastante infrecuente ya que los escasísimos estudios empíricos disponibles tienden a ser metodológicamente inconsistentes y bastante fragmentarios.

Palabras Clave: Poesía, enseñanza del inglés como lengua extranjera, motivación, percepciones, interculturalidad.

\section{INTRODUCTION}

This study explores the beliefs of trainee primary school teachers on the benefits of poetry as a tool for developing their knowledge of English as a foreign language (EFL). In doing so, we attempt to explore empirically whether the purported advantages of using literature in EFL, as suggested by scholars in the field of foreign language (FL) pedagogy, are actually in line with the opinions manifested by this group of stakeholders in the language learning process.

In contrast to the plethora of theoretical and pedagogical texts on the topic, empirical research into the use of literature (and especially poetry) in EFL is scarce. One area in which this paucity is especially noticeable concerns student beliefs (Paran, 2008). Furthermore, most available studies have adopted a microscopic approach in the sense that they inquire into a limited number of the linguistic, intercultural and motivational advantages of conducting EFL from literary texts, rather than into all of them as a whole (Akyel \& Yalçin, 1990; Carroli, 2002; Çetinavc1 \& Tütüniş, 2012; Vural, 2013; Yimwilai, 2015).

Against this fragmentary backdrop, the present study aims to provide a holistic view of the entire spectrum of literature-induced advantages in relation to the underresearched genre of poetry, and to do so using a sound and systematic methodology. To this end, the theoretically formulated advantages of literature (linguistic, intercultural, and motivation) were transformed into an 18-item questionnaire, which 
enquired specifically about the participants' views on poetry and whether or not they coincided with theoretical explorations.

We begin by reviewing the main theoretical and empirical debates surrounding literature as a tool for EFL learning before describing the research method employed in this study. The quantitative and qualitative results of the questionnaire data are then presented and discussed together with relevant pedagogical implications. Finally, conclusions and lines for further research are provided.

\section{The use of literature in EFL: State of the art and main challenges}

The use of literary texts, including poetry, in EFL has primarily been contemplated from a theoretical rather than an empirical perspective (Paran, 2008; Bobkina \& Domínguez, 2014). Most available work, generally in the form of handbooks for teachers, has tended to conceptualise the benefits that the use of literature-based lessons might bring to EFL. Such benefits have traditionally been classified into three main categories: linguistic, intercultural and motivational. Although each dimension has generally been explored separately, there is unanimous acceptance in pedagogical texts (Maley \& Duff, 1989; Lazar, 2009) and in most recent theoretical takes on the matter (Hall, 2015) that they should come together in what Collie and Slater (2009) have termed an integrated approach'. The significance of this approach to FL learning, which literature is said to facilitate, lies in the fact that linguistic, intercultural, or motivational concerns are treated as equally important, which overcomes a merely utilitarian understanding of this discipline (Hall, 2015). Considering FL learning through this psycho-social lens brings to the fore variables such as language ownership, meaningful language usage, personal expression, and critical understanding. FL learners, therefore, are considered as having multiple literacies beyond linguistic attainment to draw upon in their meaning-making processes (Hanauer, 2010).

The advantages that poetry-based lessons are alleged to bring into the EFL classroom are discussed below with reference to 'literature' in general. Two main reasons can be adduced for this: i) most of the advantages surveyed to date are applicable to all literary genres; and ii) there is a paucity of available theory and research which has focused exclusively on poetry. However, when possible, the distinction between poetry and literature in general will be clarified. The decision to conduct research into trainee teachers' beliefs on poetry as a resource for FL learning was driven by two main reasons. Firstly, the need to fully understand, in a comprehensive and systematic way, the benefits (or lack thereof) of approaching EFL through poems. Secondly, the desire to verify whether or not the fact that poetry is the least liked and the least used literary genre in EFL lessons (Akyel \& Yalçin, 1990; Kirchhoff, 2016; Duncan \& Paran, 2017) might be due to the focus of empirical 
research to date, which has examined learners' perception of literature in general rather than considering different genres individually. The holistic orientation of these studies might have been to the detriment of the perceived usefulness of specific genres, in this case poetry.

Looking now at the three dimensions in turn, firstly, within the linguistic dimension, the most recurring theoretically-established benefits of undertaking EFL from a literature-based perspective point to the development of learners' language skills along with improvement in their pronunciation and knowledge of grammar and vocabulary (Maley \& Duff, 1989; Lazar, 2009). As for the intercultural dimension, literature-based EFL instruction is believed to promote awareness not only of the cultures of English-speaking countries but also of learners' own culture (Collie \& Slater, 2009). Similarly, it is argued that motivation towards language learning increases when EFL is approached from a literary angle. This motivation has been argued to stem, on the one hand, from the affective responses elicited by literary texts - whether raising critical awareness of the world students live in (Xerri \& Xerri Agius, 2015), fostering their creativity and imagination (Lazar, 2009), or awakening their emotions (Bobkina \& Domínguez, 2014). More specifically, poetry is also believed to be a motivating EFL resource due to more formal characteristics: its nature as authentic material (McKay, 2014), its brevity (Maley \& Duff, 1989), or the non-triviality of its topics (McKay, 2014).

Theoretical and pedagogical texts outnumber empirical research on the topic, which remains scarce (Duncan \& Paran, 2017). One of the existing strands taps into the positive effects of using creative poetry writing as a means of approaching EFL (Hanauer, 2010, 2012, 2015). The extent to which literature is present in EFL textbooks has also been examined with conclusions which highlight a decrease in the use of literature-based activities in textbooks throughout the 21st century (Skela, 2014). Studies focusing on teachers have documented anecdotal use of literature in FL lessons (Gilroy, 1995).

In terms of students' beliefs, empirical studies are limited and thus in need of immediate action (Paran, 2008). By focusing on the role of the teacher, the students, and/or the task, current research has sought to document students' reactions to various teaching approaches such as reader-response (Hirvela, 1996), stylistics (Fogal, 2015), the personal model (Hirvela, 1996), the language model (Isaac, 2002) or an integrated approach (Divsar \& Tahriri, 2009). One of the insights to emerge from these studies, consistent with pedagogical approaches in EFL, is that the more student-centred the methodology, the better the student response. This makes readerresponse, the personal approach, and stylistics, in this order, the preferred methods by students (Fogal, 2015). The second insight concerns the emphasis of this research strand more along the lines of literature pedagogy than FL pedagogy, since the 
attention given to student voice has provided empirical data on what the learners think about literature as such rather than on their opinion of literature as a tool for EFL. This is reflected in Paran's insight (2008: 2) that "even when there is an engagement with language, this engagement serves a literary aim". Consequently, it seems necessary to produce research with an appropriate balance between literature and FL learning. But how should this task be undertaken? Given that the advantages of literature in EFL have tended to be established from a theoretical perspective, it would seem logical to ask students whether they find the intersection between literature and EFL of interest for English language learning. This step is likely to lead to the support, refutation, or adjustment of the theoretical positions on this topic.

Empirical research attempting to measure students' beliefs on the benefits of literature in general, and poetry in particular, is minimal. Most of it takes a microscopic approach in the sense that it solely delimits advantages within one of the three theoretical dimensions (linguistic, intercultural, motivation)-in some cases dealing even with just one variable within that dimension. Akyel and Yalçin (1990) provide data for the linguistic dimension, specifically, literature's potential to elicit communicative competence. Vural (2013), focusing on the motivation category, asks his participants whether they think learning English through literature is fun. Çetinavc1 and Tütüniş (2012) survey students about their beliefs on the utility of poems for teaching grammar and vocabulary and for enhancing learners' motivation. Carroli (2002) offers results for two variables_-'language skills' and 'culture'. Yimwilai (2015) provides findings for critical thinking skills and attitudes towards reading literature.

If our view of the advantages of literature, and specifically poetry, for EFL were to depend on the above-mentioned studies, the picture obtained would be quite limited and fragmentary, and would not do justice to the nuanced theoretical spectrum that is much more highly developed than the empirical one. This is not to say that these studies are deficient. Rather, they address the conceptualisation of advantages from a narrow perspective, possibly due to the fact that their priorities align with other concerns such as providing findings on reading habits, favourite genres or preferred approaches to the teaching of literature.

On the contrary, a more holistic approach is found in Butler (2006) and in Baba (2008), who enquire about the linguistic, intercultural and motivation dimensions. However, their treatment of the variables within each dimension might be considered overly general, since too many ideas are summarised in just one statement (Baba, 2008) or the whole spectrum of advantages within a specific dimension are not fully examined (Butler, 2006). These shortcomings prevent us from obtaining a more finely grained picture of students' attitudes towards the use of literature (and poetry) in the English language classroom. 
Instead of research designs based on a Likert scale questionnaire, more recent empirical studies such as those by Duncan and Paran (2017) and Bloemert, Paran, Jansen and van de Grift (2019) have surveyed students' perceptions by means of general, open questions about what students think the benefits of EFL literature lessons are (Bloemert et al., 2019). This design was used for the purpose of not inadvertently influencing students' answers. In Duncan and Paran (2017) this led participants to mainly acknowledge literature's potential to elicit linguistic competence, while cultural and motivational benefits were brought about to a much lesser extent. Following a similar procedure, Bloemert et al. (2019), in contrast, reported a much wider spectrum of advantages which they classified into four main approaches: the language approach (linguistic competence), the text approach (knowledge of the typical stylistic features of literature), the reader approach (personal growth), and the context approach (socio-historical knowledge of the period in which the literary text was written). Even though we agree that surveying non-mediated views can provide valuable insights into students' beliefs, we also consider that asking students to react to specific issues or ideas might also be useful for our specific goals, namely to support or refute available theoretical positions on the use of poetry in EFL.

In light of the issues outlined above, the potential contribution of the present study to existing research on literature and foreign language learning is considerable. Not only does it explore students' views by means of a questionnaire, which surveys the theoretically-formulated advantages of using poetry for EFL in their entirety, but it does so using a methodology which is both sound and systematic. The two research questions which guide this study are: Do learners perceive theoretically defined advantages of poetry in EFL? How do they rate those advantages?

\section{Methodological framework}

\subsection{Participants}

The participants in the study were 270 undergraduate trainee teachers in their third year of a four-year degree in Primary Education at a University in southeast Spain. The majority of the students were female ( $78 \%$ of the sample), which reflects the general tendency for more women than men to enrol in university studies relating to the teaching profession. The ages of the participants ranged from 21 to 60 years old, although the mean age was 21.72. All the students were taking a compulsory EFL module at a B1 level of competence according to the Common European Framework for Languages (2001), although they were not specialist language teachers. This was an option available to students in the final year of their degree. According to information from their class teachers, and despite studying English for over twelve years throughout primary and secondary education, the students' levels of English were generally lower than would be desirable to comfortably pass the course. The 270 
participants were divided into six classes of around 45 students taught by four qualified non-native speakers of English and one qualified native-speaker teacher. In selecting these students, convenience sampling was used for ease of accessibility in administering the survey.

The decision to survey trainee teachers was motivated by the assumptions that their existing knowledge of pedagogy might prompt them to provide thorough, finegrained and insightful reactions and that raising their awareness about the whole spectrum of advantages of using poetry for EFL might help them implement a view of this discipline which is not merely instrumental but at the crossroads of linguistic, intercultural and socio-critical competences.

\subsection{Instruments, data collection, and analysis}

The instrument consisted of a questionnaire aimed at determining the perceptions held by future primary school teachers concerning the potential of poetry as a resource for learning English. It contained 18 statements to be scored on a 7-point Likert scale, with a score of 1 corresponding to complete disagreement with the given statement and 7 to full agreement. After each item a blank space was provided for students to justify in writing their numerical valuations in as much detail as possible based on their personal experiences or perceptions. Nearly $50 \%$ of the students completed this part. Of this percentage, a minority justified their answers soundly while most of the respondents simply repeated the ideas in the statements but with different wording.

To design the questionnaire, firstly, a series of items was shortlisted from theoretical studies of the alleged benefits of literature for teaching and learning a foreign language and adapted to refer specifically to poetry. Next, three experienced specialist EFL associate professors were invited to comment on the questionnaire and refinements were made where necessary. This process resulted in the final 18-item questionnaire (see Table 3). The instrument was then piloted with a group of 40 final year EFL students at the same university to ensure that all items were sufficiently clear. Their suggestions allowed us to rephrase problematic items.

Following the pilot run, the internal consistency of the survey instrument was established by calculating Cronbach alpha coefficients for each of the three dimensions. The reliability coefficients for the linguistic (0.862), intercultural (0.785) and motivational (0.918) dimensions were within the acceptable range for an exploratory study (Kormos \& Csizer, 2008). A standardized principal component analysis (PCA) was also run on the data and it was observed that 3 factors accumulated more than $62 \%$ of the variance (Table 1 and Figure 1). These values validated the theoretically established 3-dimension model developed by scholarly research to classify the advantages of using literature in EFL. 
Table 1. Principal Component Analysis (PCA).

\begin{tabular}{|c|c|c|c|}
\hline Component & Total & \% of Variance & \% Cumulative Variance \\
\hline 1 & 8.291 & 46.06 & 46.06 \\
\hline 2 & 1.825 & 10.14 & 52.2 \\
\hline 3 & 1.084 & 6.02 & 63.23 \\
\hline
\end{tabular}
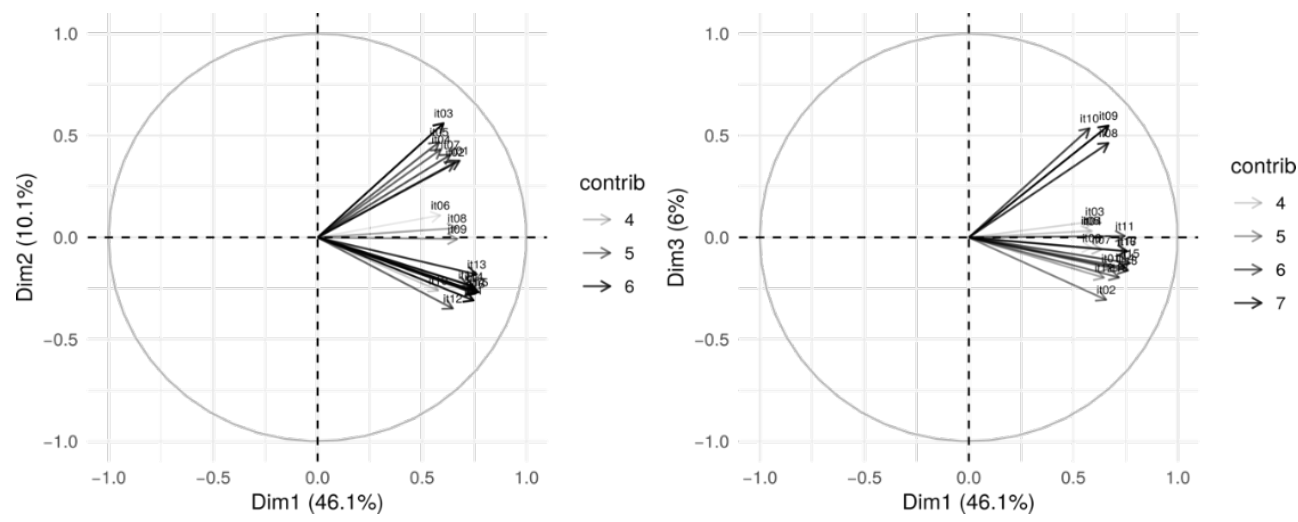

Figure 1. PCA Variables: Dimensions 1 and 2 and dimensions 1 and 3.

The questionnaire was administered by the students' EFL teachers during their English classes. Each student was required to indicate his or her personal identification number on the statistical data sheet, which accompanied the survey, and to rate each item from 1 to 7 by marking the corresponding numerical box. This process was completed in 40 minutes.

To analyse the data, the students' raw responses for each item were computed and grouped into three main levels (low, neutral and high) for interpretative purposes. The low level comprised all ratings from 1 to 3 (from 'Strongly disagree' to 'Slightly disagree'). The neutral level comprised answers rated as 4 ('Neither agree nor disagree'), while the high level agglutinated answers from 5 to 7 (from 'Slightly agree' to 'Strongly agree'). The frequencies of the students' responses were then calculated as percentages together with the means scores and the standard deviation. Both percentages and means were calculated to provide more in-depth information on the distribution of the trainees' responses.

The qualitative data were analysed according to an inductive three-stage process (Braun \& Clarke, 2006), carried out by all three researchers. Firstly, the participants' comments for each dimension and each item (Annex) were carefully read and 
quantified. Then recurrent ideas for each item, both positive and negative, were identified and quantified in terms of whether they highlighted a perceived advantage or disadvantage. Finally, representative statements were selected to illustrate the numerical results at the low and high levels on items from the three main dimensions (Table 2).

Table 2. Examples of positive and negative comments.

\begin{tabular}{|l|l|}
\hline $\begin{array}{l}\text { Positive } \\
\text { comments }\end{array}$ & $\begin{array}{l}\text { - For an hour-long class a poem is perfect as you can finish reading it (item 11: } \\
\text { conciseness). } \\
\text { - Since poetry deals with general topics which I have experienced myself, I find it easy to } \\
\text { relate to what the poet is feeling (item 15: understand other people's emotions). }\end{array}$ \\
\hline $\begin{array}{l}\text { Negative } \\
\text { comments }\end{array}$ & $\begin{array}{l}\text { - Poems are short but very difficult to interpret (item 11: conciseness). } \\
\text { - For me poetry is not beautiful as I have difficulty understanding it (item 18: aesthetic } \\
\text { pleasure). }\end{array}$ \\
\hline
\end{tabular}

\section{Results}

The quantitative results of the questionnaire data are presented for each dimension-linguistic, intercultural, and motivation-and for individual items within each of the dimensions (Table 3). The second part of this section examines the comments made by students with a view to identifying the reasons underlying the quantitative scores they provided. 
Table 3. Item frequency. Levels: low, neutral and high.

\begin{tabular}{|l|l|c|c|c|c|c|}
\hline \multicolumn{2}{|l|}{ DIMENSIONS AND ITEMS } & \multicolumn{4}{l|}{ Sow } \\
\hline $\begin{array}{l}\text { USING POETRY AS A TOOL FOR EFL CAN } \\
\text { HELP ENHANCE }\end{array}$ & $\begin{array}{c}\text { Low } \\
\mathbf{( \% )}\end{array}$ & $\begin{array}{c}\text { Neutral } \\
\mathbf{( \% )}\end{array}$ & $\begin{array}{c}\text { High } \\
\mathbf{( \% )}\end{array}$ & Mean & Sd \\
\hline & MY LINGUISTIC COMPETENCE & 13.06 & 21.73 & 65.21 & 4.96 & 1.26 \\
\hline 1. & my reading skills & 18.52 & 24.81 & 56.67 & 4.66 & 1.28 \\
\hline 2. & my writing skills & 17.78 & 25.19 & 57.04 & 4.70 & 1.34 \\
\hline 3. & my speaking skills & 15.19 & 26.67 & 58.15 & 4.76 & 1.30 \\
\hline 4. & my listening skills & 16.48 & 22.47 & 61.05 & 4.76 & 1.26 \\
\hline 5. & my pronunciation & 10.04 & 15.24 & 74.72 & 5.24 & 1.33 \\
\hline 6. & my grammar & 10.11 & 26.97 & 62.92 & 4.95 & 1.28 \\
\hline 7. & my vocabulary & 3.35 & 10.78 & 85.87 & 5.67 & 1.08 \\
\hline & MY INTERCULTURAL COMPETENCE & 25.15 & 25.50 & 49.35 & 4.41 & 1.34 \\
\hline 8. & $\begin{array}{l}\text { my understanding of people from English-speaking } \\
\text { countries }\end{array}$ & 25.19 & 28.52 & 46.30 & 4.34 & 1.25 \\
\hline 9. & $\begin{array}{l}\text { my awareness of the culture of English-speaking } \\
\text { countries }\end{array}$ & 24.34 & 19.10 & 56.55 & 4.58 & 1.33 \\
\hline 10. & my understanding of my own culture & 25.93 & 28.89 & 45.19 & 4.33 & 1.44 \\
\hline & MY MOTIVATION TO LEARN EFL & 21.17 & 24.88 & 53.95 & 4.54 & 1.34 \\
\hline 11. & because poems are authentic material & 25.56 & 23.70 & 50.74 & 4.44 & 1.34 \\
\hline 12. & because poems are short texts & 22.96 & 27.04 & 50.00 & 4.39 & 1.33 \\
\hline 13. & because topics in poems tend to be non-trivial & 15.93 & 26.67 & 57.41 & 4.71 & 1.25 \\
\hline 14. & $\begin{array}{l}\text { because working with poems encourages me to } \\
\text { express my opinions and feelings }\end{array}$ & 21.56 & 21.19 & 57.25 & 4.64 & 1.40 \\
\hline 15. & $\begin{array}{l}\text { because poems help me talk about and understand } \\
\text { other peoples' emotions and feelings }\end{array}$ & 20.82 & 19.33 & 59.85 & 4.74 & 1.41 \\
\hline 16. & $\begin{array}{l}\text { because working with poems makes me use my } \\
\text { interpretative skills and not only my knowledge of } \\
\text { the language }\end{array}$ & 23.88 & 29.85 & 46.27 & 4.28 & 1.23 \\
\hline 17. & $\begin{array}{l}\text { because poems deal with values that might have a } \\
\text { positive impact on me or on the world around me }\end{array}$ & 19.70 & 30.86 & 49.44 & 4.42 & 1.27 \\
\hline 18. & because poems are beautiful & 18.96 & 20.45 & 60.59 & 4.76 & 1.52 \\
\hline
\end{tabular}

An overall comparison of the three dimensions reveals that the articulation of linguistic knowledge was perceived by the respondents as the most important contribution of poetry to EFL classes, with $65.21 \%$ of the trainees rating the development of linguistic competence highly. The figures for the intercultural and the motivation dimensions, if positive, were substantially lower, with $49.35 \%$ and $53.95 \%$ of the participants assigning a high rating to these items.

Within the linguistic dimension, over half of the respondents valued reading (item 1, 56.67\%), writing (item 2, 57.04\%), speaking (item 3, 58.15\%), and listening (item 4, $61.05 \%$ ) positively, adding further support to the idea that poetry was considered a useful tool for promoting communication and developing language skills in the classroom. Higher percentages still were also found for specific components of language, including grammar (item 6, 62.92\%), vocabulary (item 7, 85.87\%) and, especially, pronunciation (item $5,74.72 \%$ ). 
The results for the intercultural dimension (items 8-10), with percentages at the higher end of the scale ranging between $45.19 \%$ to $56.55 \%$, suggest that around half of the participants considered poetry not only as a sound means of developing cultural knowledge of the L2 (items 8 and 9), but also that knowledge of the L2 could lead to a clearer awareness of their own culture (item 10).

Within the motivation dimension, items 11-13 aimed to measure the trainees' views regarding formal aspects of poetry such as its nature as authentic material, its length, and the non-triviality of its topics. The authenticity of poetry (item 11) was perceived as its most advantageous attribute, with $50.74 \%$ of participants rating this item highly. The reduced length of poems (item 12) and their focus on non-trivial topics (item 13) were also highly valued by $50 \%$ and $46.27 \%$ of the trainees respectively. As for the affective side of motivation, which working with poems is believed to bring into EFL (items 14-18), item 18, which referred to poetry's potential to create a beautiful experience for the reader, was rated highly by $60.59 \%$ of the respondents. A further $57.41 \%$ were in favour of learning EFL through the active, self-discovery approach which poetry encourages (item 16). Items 14 and 15, which sought to establish to what extent trainees believed poetry-mediated English lessons might be useful for understanding and expressing emotions, both their own and other people's, were rated highly by $57.25 \%$ and $59.85 \%$ of the participants respectively. Just under half of the trainees (49.44\%) also considered favourably that the use of poetry in EFL might embody potential as an agent of social change (item 17).

\subsection{Qualitative breakdown of results}

\section{Linguistic dimension}

The analysis of the trainees' written comments in response to the questionnaires revealed recurrent opinions and rationales which facilitated the interpretation of the numerical data. To focus firstly on the linguistic dimension, the positive view that poetry might help learners to improve reading skills in the EFL class (item 1) was linked to two main ideas: the typical brevity of poems and the perceived non-triviality of its topics, mentioned by five and thirteen students respectively. Regarding length, one student highlighted as an advantage the fact that 'you do not get tired when reading them'. Shortness, however, appears as a double-edged sword since, for two students who had assigned a low value to this item, the conciseness of poetic texts was considered a disadvantage on the grounds that, 'Poetry isn't very useful for practising reading as poems are very short'. It appears that, for these learners, reading seemed to be more equated with 'extensive' reading. The same principle might apply to how the non-triviality of poetic topics affected opinions on the development of reading skills. While most students acknowledged that interesting topics increased their motivation to read in English, those participants who disagreed expressed a concern regarding the complexity of the topics dealt with, as evidenced in the following comment: 
'Developing reading skills with poetry is counterproductive as the topics are generally complicated and they do not invite you to continue reading'.

The value of poetry for developing writing and speaking skills (items 2 and 3) was commented on extensively. As with reading, the key issue here was the non-triviality of poetic topics, which ten respondents highlighted as 'interesting', 'different' or 'attractive' to talk or write about. Regarding speaking, one participant commented: 'English lessons do not motivate you to talk as the topics are usually boring. I think that the topics covered in poetry could be more interesting. It is a different way of learning English'. The low number of respondents who did not appear to appreciate the potential of poetry to foster their writing (1 respondent) and speaking skills (1 respondent) attributed this to the 'obscurity' of poetic topics, especially if learners do not have a good level of English. Two further negative opinions worth consideration, which have not been contemplated in research to date, concern the participants' unwillingness to talk or write about the private matters which poems are perceived to deal with. In reference to speaking, one student remarked 'I don't feel comfortable talking in class about private feelings and emotions. I prefer to talk about less personal things-, while two respondents noted that some poets' articulation of feelings were too 'strange' or 'dramatic' and therefore 'too distant' from their own life experiences. The lack of oral practice in classrooms was also mentioned by another student: 'Discussing poems could help me improve my speaking in English. However, in English classes, at least in my case, we never did any speaking; we only studied grammar and did fill-the-gap exercises'.

Poetry was also considered a highly useful tool for developing learners' listening skills (item 4). Most of the participants' written comments emphasized how listening to poems, either read aloud or dramatized, could help them imitate or get phonemes right (5 students). One learner also pointed out that poems are perfect examples of texts that can be read aloud or recorded so that learners can listen for the main ideas, and not just for the phonemes. No comments were provided which would have enabled us to identify the rationale underlying the view held by a limited percentage of the population, who indicated that poetry was not a useful means of improving listening in English.

As for pronunciation (item 5), twenty-one students pointed out that reading aloud-given the rhythmic nature of poetry - was useful for assimilating the sounds and intonation of the language. Evidently, this perceived advantage can only be triggered if reading aloud is undertaken in the classroom, a fairly infrequent practice, according at least, to the opinions of two informants: 'Reading aloud poetry or any other text in English is helpful for learning phonetics although we seldom do this in class, and when we do it the teacher only corrects pronunciation superficially, probably because it takes up a lot of time'. Consequently, although the trainees 
seemed to appreciate the value of poetry in helping them improve their pronunciation when read aloud, they also acknowledged that the oral feature of poetry tends to be underexploited in class.

Regarding grammar and vocabulary (items 6 and 7), thirteen and twenty-five students respectively highlighted the possibility of acquiring a more sophisticated model of language through working closely with poetry, a language model which one student labelled as 'cultured' and which he posed as the level of language speakers should target. No negative comments were provided for these two items.

\section{Intercultural dimension}

Within the intercultural dimension, the participants' largely neutral perceptions (items 8-10) might be attributed to their inability to add any further nuances to the ideas already expressed in the formulations of the items themselves. However, two negative issues arose from the data: i) the idea that L1 and L2 cultures are different, watertight, and cannot mutually benefit from each other (4 students); and ii) the idea that poetry is unrelated to the expression of culture (3 students). The following comment clearly illustrates the first idea: 'British culture has nothing to do with Spanish culture. They are both totally different and you cannot relate them. I do not need to know British culture to know what I am like as a Spaniard'. The inflexible and inward-looking view of culture illustrated in this rationale was also identified in relation to the underexploited role of the L2 culture in strengthening learners' knowledge of their native culture. This notion is exemplified in the following comment: 'You only really see the strong and weak points of each culture when you compare them. In Spain we're not good at English as we are too self-centred'.

The second issue concerning the perceived inexistence of an association between poetry and the expression of culture, as expressed by three informants, seems to respond to a misperception on the part of the respondents of what poetry is: 'Poetry deals with general feelings and not with any specific culture', as one of the trainees put it. This negative comment may stem from the belief that poetry is associated exclusively with the expression of lyricism, which, considering the variety and types of poetry available, is not the case. It also reflects the assumption that feelings are homogeneously expressed across different cultures, which, once again, does not correspond with reality.

\section{Motivational dimension}

Turning to the motivational dimension, the positive views expressed in relation to the authenticity of poems (item 11) seemed to emerge from the students' awareness that behind a poem there is a real person and that makes the learning experience seem 'real' (2 comments), and from their acknowledgement of the artificial nature of the topics generally found in EFL textbooks (6 comments), to which one student even 
referred as 'silly'. Although authenticity was highly valued, three students perceived it as a problematic feature based on the 'difficulty' or 'abstractness' of poems.

The participants' motivation in relation to the conciseness of poetry was supported by two main rationales. On the one hand, four students sustained the view that the brevity of poems keeps them from getting tired when working with these text-types'If I read in English for too long I get tired and bored'. This same argument was also brought up to justify positive views on how poetry might help develop reading skills. Shortness was also mentioned by three participants as beneficial for time management in the English class, since they considered that a poem could perfectly fit the duration of a lesson. As one informant stated: 'For an hour-long class a poem is perfect as you can finish reading it and not waste time in the next class trying to remember what it was that you had read before'. As for the trainees whose views on the shortness of poems did not coincide with their peers, it seems that text length was less important for them than understanding the poem, which they felt was more likely to occur when reading other types of texts: 'Poems are short but very difficult to interpret. I prefer parts of novels or news items from the press or the Internet'.

Regarding the non-triviality of poetic topics (item 13), no positive comments were made, which, once again, leads us to assume that participants may have felt the item fully represented their view on the matter. The five negative comments identified were based on the idea that the themes found in poetry were 'interesting but too difficult to interpret' (3 comments) or simply 'too abstract and impractical' (2 comments).

Opinions on the aesthetic pleasure which poetry is likely to elicit in EFL learners (item 18) suggested that poetry could enhance feelings of calmness (2 comments) 'when I read poetry I feel peaceful as the images are beautiful and make you feel calm'-, comfort when things in life go wrong (2 comments) - Poetry enables you to imagine beautiful situations that make you feel better, especially if you are feeling down or have problems'-, or goodness/kindness (4 comments) - 'Poetry is beautiful as it generally talks about love or happiness'. The orality of poetry, in this case through the association between poetry and music, was also conceived as a source of beauty in EFL ( 2 comments): 'When poetry is heard as a song I can appreciate its beauty even more. In English I have never listened to poems as songs, but in Spanish literature classes in secondary school the song versions of Antonio Machado's or Federico García Lorca's poems made me appreciate the beauty of the poems and the content even more'.

Two main reasons accounted for the negative perception expressed as regards the beauty of poetry. On the one hand, the perceived difficulty of poetic topics was felt to short-circuit any possibility of experiencing beauty ( 2 comments): 'For me poetry is not beautiful as I have difficulty understanding it'. On the other hand, issues of perceived emotional distance and artificiality ( 3 comments) also seemed to interfere 
with aesthetic value, as the following comment show: 'I do not really consider poetry beautiful because the content and the way it is expressed does not relate to my understanding of life; it does not have anything to do with who I am'.

The active, self-discovery approach which learning English through poetry encourages (item 16) was highlighted by five students, especially in relation to the pleasure of disentangling rhetorical figures: 'I enjoy trying to understand and decipher the metaphors in poetry'. The demands of the interpretative process, however, might also justify the three negative opinions reported: 'To understand a poem in English you have to read it several times. This is really boring and I usually get fed up' or 'The language and the content of poetry is difficult and therefore I lose interest in the class'.

The positive perception of poetry as a means of encouraging the expression of personal opinions and feelings (item 14) was reported by five participants in terms of the personal enrichment they obtain when given the chance to compare their own emotions with those of others': 'Poets express what they feel through their poems and I like knowing how other people feel about topics like love, happiness or death and comparing them with my own. I find it enriching'. When justifying the ability of poetry to help understand the emotions of others' (item 15), three informants emphasized their empathy with the universality of poetic themes: 'Since poetry deals with general topics which I have experienced myself, I find it easy to relate to what the poet is feeling. The negative comments reported for these two items ( 2 for item 14 and 3 for item 15), once again, stemmed from the perceived difficulty of poetic topics, in this case their metaphorical nature or their multivocality. The following comment seems to point in this direction: 'It is better not to use texts with different meanings to learn English, but ones in which the writer's intentions are clearer'.

The transmission of values which working with poetry is likely to encourage (item 17), did not receive any positive comments. The two negative responses expressed by participants were related to the idea that poetry is simply a lyrical genre-a misperception which deprives poems, for instance, of the contestatory potential they undoubtedly have: 'Poetry cannot change the world. It deals with emotions not social values'.

\section{Discussion}

The research questions that guided the present study asked: Do learners perceive theoretically defined advantages of poetry in EFL? How do they rate those advantages? The results obtained from the questionnaire data confirm that the primary school teacher trainees surveyed in this study consider that using poetry as a tool in the EFL classroom is likely to have a positive impact primarily on their linguistic competence, but also on their motivation to learn the L2 and, to a lesser extent, on the development of intercultural competence. The development of lexical knowledge, improved pronunciation and grammar stand out respectively as the most 
highly valued attributes of poetry with means close to and above 5 , as indicated by the majority of the participants (between 62\% and 85\%). Alongside these positive results, the remaining linguistic, intercultural and motivational issues targeted by the questionnaire obtained mainly neutral responses with means clustering between 4.28 and 4.76. These issues will be considered below.

The fact that the variables within the intercultural and motivation dimensions were not as highly valued as those in the linguistic dimension seems to foreground that, for around half of the students, EFL is essentially an instrumental endeavour. This perception might be engrained in them from their own schooling and their teachers' understanding and implementation of this discipline. In instructed learning environments in Spain, the teaching of EFL commonly focuses on the acquisition of linguistic structures and lexis rather than the development of communicative competence. In this sense, the conception of language that emerges from the examination of their beliefs on poetry as a tool for EFL suggests that the semiotic dimension of language is more highly valued by these students than the pragmatic dimension. This might explain why, within the linguistic dimension, skills development (listening, speaking, reading and writing), while still perceived as advantages, obtained lower ratings than those for vocabulary, grammar, and pronunciation. This might also explain why their perceptions of the three dimensions were not evenly matched, since without sufficient previous knowledge and experience of using poetry as tool for learning English, perceived linguistic benefits prevailed over possible intercultural and motivational considerations.

The emphasis on the linguistic benefits of using poetry as a tool for EFL enters into conflict with the proponents of the literature-based approach to EFL who have tirelessly established that its main advantages are, precisely, the enhancement of intercultural aspects and, especially, personal growth (Bobkina \& Domínguez, 2014). However, far from discouraging, the findings of the questionnaire data might be considered promising for several reasons; not only do they confirm that the majority of the future teachers in this study readily acknowledge the benefits of poetry as a language teaching tool, but that motivational and intercultural benefits, while still lagging behind, are valued more positively than not. For EFL to be fully conceived as the encounter of linguistic, intercultural and motivation drives, it seems that the current conceptions held by the trainees might need to be more finely tuned through pedagogical approaches which bring to light the multiple contributions poetry can make to L2 development.

A more detailed examination of each of the participants' responses within each of the three dimensions (linguistic, intercultural and motivational) revealed coincidences not only with theoretical insights into the role of poetry in EFL (Lazar, 2009; Hall, 
2015), but also with the findings of the few available empirical studies that have addressed this issue. These will be discussed below.

\section{Linguistic dimension}

The positive perceptions reported in this study towards the use of poetry as an elicitor of EFL linguistic competence is congruent with a plethora of work which has explored the matter both theoretically and empirically (Lazar, 2009; Hall, 2015; Duncan \& Paran, 2017). Regarding whether poetry-based EFL lessons might contribute to the development of language skills, Baba (2008), drawing on 170 Malayan informants, reports that, to the question ' $I$ think the use of literature in language teaching will help to improve my language skills such as writing, reading and speaking', 73\% of students strongly agreed or agreed. However, Baba's enquiry into literature's potential to elicit linguistic knowledge is limited exclusively to this single item, which clearly prevents us from establishing possible comparisons with our participants' perceptions of the three components it includes (lexis, pronunciation and grammar). Baba's study does not offer additional quantitative results for these key aspects of EFL, which, according to theoretical models, poetry has the potential to enhance (Maley \& Duff, 1989; Lazar, 2009).

Butler (2006) also reports positive attitudes towards the use of literature as a tool for language learning, with 64 of 85 the undergraduates in his study reporting improved proficiency in English as the privileged advantage of the cross-fertilisation of literature and EFL. As with Baba (2008), however, this study fails to conceptualise the whole theoretically-defined spectrum of the linguistic advantages of literature. In an empirical study with 635 Dutch secondary school students, Bloemert et al. (2019) suggest that the development of language skills is a benefit commonly alluded to by students. However, once again, a breakdown of specific skills was not provided. The qualitative data which Duncan and Paran (2017) obtained from the analysis of student discussions, student focus groups and open questionnaires confirmed that learners in three different European German-speaking, English-speaking and French-speaking schools, considered literature-based lesson to be appropriate for the acquisition of language skills, especially reading, in their FL classes. The genre which was perceived to be most useful in this respect was the novel and, to a lesser extent, plays, poems and literary essays.

The widespread belief held by trainees on the potential of poetry to improve pronunciation in the L2 coincides with views expressed, for example, by Lazar (2009). The perceived advantage of poetry in relation to grammar and vocabulary is in line with results reported by Çetinavcı and Tütüniş (2012), whose positive values for the acquisition of both elements had means of 3.52/5 and 3.66/5. Bloemert et al. (2019) also posit vocabulary improvement as the second most alluded to advantage of teaching EFL through literary texts, with $44 \%$ of their informants highlighting their 
contribution to the promotion of lexical knowledge in the L2. Qualitatively, Duncan and Paran (2017) reach the same conclusion.

The positive perception held by EFL learners, including our future teachers, of poetry as a potential facilitator of grammar and vocabulary acquisition challenges two of the arguments most frequently put forward by critics of the use of poetry in EFL. These include, firstly, its detrimental effect on the development of language skills based on poetry's lexical difficulty, and secondly the deviation which poetic language entails from the conventions and rules underlying standard discourse (Lima, 2010). Surprisingly, the two benefits most widely highlighted by authors when advocating the use of poetry as a means of developing grammar and vocabulary, its memorability (Lazar, 1990) and the creativity of literary texts in contrast to the "bland correctness of specially written ESL textbooks" (Boggs, 1997: 64), were not mentioned by our informants perhaps due to their lack of an in-depth understanding of the stylistic features of poetic discourse.

\section{Intercultural dimension}

The views expressed by around half of our future teachers in relation to the development of cultural awareness align with theoretical stances on the matter, which highlight the impossibility of really acquiring an L2 without truly understanding its culture (Byram, 2008). Empirically, Baba (2008) reports high agreement with this feature of literature with values of $80 \%$ noted for its potential to contribute to intercultural awareness and $79 \%$ regarding its effectiveness in helping students develop a deeper understanding of their own culture. Bloemert et al. (2019) claim that $47 \%$ of the subject sample they surveyed (635 individuals) emphasized cultural awareness of the L2 as the most beneficial outcome of teaching EFL through literature. Carroli (2002) and Butler (2006) document much lower rates of agreement (13 students out of 39 and 4 out of 85 respectively). This might be due to the nature of their research whose primary focus was not on obtaining information on the usefulness of literature for EFL but on determining general reasons why students liked literature. Entertainment value (Carroli, 2002) and improved language proficiency (Butler, 2006) received the highest ratings in these studies. In Duncan and Paran's (2017) qualitative study, literature's contribution to raising cultural awareness of the L2 in FL classes is widely appreciated.

\section{Motivational dimension}

Poetry was also considered to enhance motivation for L2 learning. Favourable takes on the authenticity of poems, the conciseness of poetry and the non-triviality of poetic topics coincide with theorists' and researchers' opinions that students' motivation to learn English through poetry relies, among other factors, on their appreciation of the typical formal characteristics of this literary genre (Lazar, 2009). 
Similarly, the belief held by many of the trainees that poems can encourage students to express their emotions and understand those of others coincides with Xerri and Xerri Agius' views (2015) that poetic texts in EFL are self-empowerment and empathyraising artefacts.

The activation of high order thinking skills necessary to access the meaning of poetic texts is another aspect which many of the participants signalled as likely to boost their motivation. In doing so, they corroborate theoretical and empirical insights (Martin, 2000; Lazar, 2009; Bloemert et al., 2019) that, to use Martin's words (2000: 11): "the confidence gained in one's own problem-solving strategies [when a poem is used for EFL] is probably at least as important as the results of interpretations themselves". Students and theorists and researchers alike draw attention to the notion that motivation in EFL does not only come from learning the language itself but also through students' awareness that they become owners of their meaning-making processes—something that poetry might allow them to do. In fact, Yimwilai (2015) demonstrates that literature-based lessons lead to the activation of more and higher critical thinking skills than conventional instruction, which empirically validates both theoretical insights and the beliefs of the participants in this study.

The perception held by around half of the trainees that poetry might help raise socio-critical consciousness in EFL classes seems to align with a strand of EFL (Crookes, 2013; Xerri \& Xerri Agius, 2015) that advocates an understanding of this discipline at the crossroads of the development of communicative competence and the increase of critical consciousness towards ourselves and the world around us as a way of promoting social justice. Empirically, Carroli (2002), Butler (2006), Baba (2008) and Vural (2013) also document a high level of agreement with the idea that literaturebased classes can lead to an increase in students' motivation by means of 'personal development' or the delivery of more 'relaxed', 'entertaining', 'fun' or 'interesting' classes. These enquiries into motivation, however, do not provide information on what specifically it is that students find 'fun' or 'personally-enriching' about literaturebased English lessons. For this reason, the present study is unique in tapping into our trainees' perceptions of the whole spectrum of motivational benefits: authenticity, compactness, non-triviality of topics, expression of opinions, activation of critical thinking and socio-critic awareness, and aesthetic pleasure.

Motivation has also been held to emerge from experiencing the beauty of literary texts. Empirical data on this aspect of motivation are not abundant and those available are limited to observing students' capability of recognising beauty in literature but without exploring where it comes from or what students understand by it (Carroli, 2002; Butler, 2006). Consequently, the previously mentioned insights regarding the role of aesthetic pleasure in EFL are especially significant since it would appear to be the first time empirical data have been obtained on this issue. 


\subsection{Implications for using poetry in EFL}

Two factors emerge from the qualitative opinions expressed by participants in the present study that are seen to impede the success of poetry-based lessons: impoverished teaching practice and students' misperceptions of this genre. Poor teaching practice manifests itself in teachers failing to correct pronunciation difficulties or not encouraging students to read poetry aloud in class, while the trainees' conception of poetry as a lyrical genre that deals solely with emotions greatly distorts its scope of action, including the potential of poetry to deal with social issues.

To resolve such a restrictive view of poetry, teachers might be helped to become more aware of learners' previous experiences with this genre, not only in EFL but also in their mother tongue, and to identify the reticence and frustrations that might have arisen from past poetry lessons. As Jean (1996) claims, the study of poetry tends to focus on learning its historical background, which disregards the oral bodily substratum underlying this genre- the experience of breathing, pauses, rhythms, and sounds. It is possible, therefore, that the role given to poetry in L2 learning is not likely to improve unless there is a considerable change in how it is conceived in the L1.

A further issue concerns careful topic selection, which was recurrently mentioned. Problems are likely to arise if learners find the theme of the poem too abstract, dramatic, difficult, or even too distant from their own perception of the topic being dealt with. Text-selection criteria thus seem to be instrumental in reducing student anxiety in this respect. Fortunately, this is a well-researched area and some comprehensive models exist (Lazar, 2009; Lima, 2010).

\section{CONCLUSION}

The findings reported from the questionnaire responses confirm that the eighteen theoretically established advantages regarding the use of poetry as a tool for EFL are also perceived as such by the majority of the trainees surveyed. These results are consistent with the limited empirical research available. Indeed, for some of the variables under study, this is the first time empirical data have been obtained. This is the case with the affective variables within the motivation dimension, specifically the non-triviality of poetry, the intra and interpersonal expression of feelings and the cognitive, social and aesthetic impact it may have on learners. In the same way, some of the reasons articulated by trainees in favour or against using poetry have not yet been conceptualised in empirical research to date. These include the observation that poetry is useful in acquiring a cultivated register in the L2, or the unwillingness to talk publicly in the L2 class about the private matters that are often the subject of poetry. By uncovering learners' beliefs on poetry as an under-explored literary genre, the study contributes to the empirical expansion of the field, a line of research signalled as a 
priority by theorists and researchers alike (Carter, 2007; Paran, 2008). This study has also shown that future teachers are willing to learn English through poetry, which suggests that literature-mediated lessons might be the key to boosting students' motivation — an issue of the utmost importance in foreign language learning (Dörnyei, Henry \& Muir, 2016). It would now seem appropriate for EFL teachers and textbook publishing houses to adopt more positive views on the intersection of poetry and EFL, an intersection that to date has received very little attention.

Future research on the use of poetry in EFL is clearly warranted. Researchers might compare students' perceptions of poetry before and after engaging in poetrybased lessons, extending the data base to include learners of different ages and proficiency levels. The perceptions of both experienced and novel EFL teachers' might also be explored. A further line of enquiry might include tapping into the potential language learning benefits of working with poetry and other literary genres.

\section{REFERENCES}

Akyel, A. \& Yalçin, E. (1990). Literature in the EFL class: A study of goalachievement incongruence, 44(3), 174-180.

Baba, W. K. (2008). An investigation into teachers' and students' attitudes towards literature and its use in ESL classrooms: A case study at a matriculation centre in Malaysia. Unpublished doctoral dissertation, University of Leicester, Leicester, United Kingdom.

Bloemert, J., Paran, A., Jansen, E. \& van de Grift, W. (2019). Students' perspective on the benefits of EFL literature education. The Language Learning Journal, 47(3), 371-384.

Bobkina, J. \& Domínguez, E. (2014). The use of literature and literary texts in the EFL classroom; between consensus and controversy. International Journal of Applied Linguistics \& English Literature, 3(2), 248-260.

Boggs, R. (1997). A Shakespeare sonnet in Khartoum: The context of culture and the interpretation of text. In A. C. McLean (Ed.), SIG selections 1997: Special Interests in ELT (pp. 64-68). Whitstable: IATEFL.

Braun, V. \& Clarke, V. (2006). Using thematic analysis in psychology. Qualitative Research in Psychology, 3(2), 77-101.

Butler, I. (2006). Integrating language and literature in English studies: A case study of the English 100 course at the University of North West. Unpublished doctoral dissertation, University of South Africa, South Africa.

Byram, M. (2008). From foreign language education to education for intercultural citizenship. Essays and reflections. Clevendon: Multilingual Matters. 
Carroli, P. (2002). Perceptions of literature: A comparasion of students' and educators' views. Proceedings of Innovations in Italian Teaching Workshop (pp. 113-128). Griffith: Griffith University.

Carter, R. (2007). Literature and language teaching 1986-2006: A review. International Journal of Applied Linguistics, 17(1), 3-13.

Çetinavc1, U. R. \& Tütüniş, B. (2012). Making use of poems to teach English. The Journal of Language Teaching and Learning, 2(2), 75-88.

Collie, J. \& Slater, S. (2009). Literature in the language classroom: A resource book of ideas and activities. Cambridge: Cambridge University Press.

Crookes, G. (2013). Critical ELT in action: Foundations, promises, praxis. New York: Routledge.

Divsar, H. \& Tahriri, A. (2009). Investigating the effectiveness of an integrated approach to teaching literature in an EFL context. Journal of Pan-Pacific Association of Applied Linguistics, 13(2), 105-116.

Dörnyei, Z., Henry, A. \& Muir, C. (2016). Motivational currents in language learning: Frameworks for focused interventions. New York: Routledge.

Duncan, S. \& Paran, A. (2017). The effectiveness of literature on acquisition of language skills and intercultural understanding in the high school context. London: Institute of Education. UCL.

Fogal, G. G. (2015). Pedagogical stylistics in multiple foreign language and second language contexts: A synthesis of empirical research. Language and Literature, 24(1), 54-72.

Gilroy, M. (1995). An investigation into teachers' attitudes to using literature in the language classroom. Edinburgh Working Papers in Applied Linguistics, 6, 1-17.

Hall, G. (2015). Literature in language education. New York: Palgrave.

Hanauer, D. I. (2010). Poetry as research: Exploring second language poetry writing. Amsterdam: John Benjamins.

Hanauer, D. I. (2012). Meaningful literacy: Writing poetry in the language classroom. Language Teaching: Surveys and Studies, 45(1), 105-115.

Hanauer, D. I. (2015). Measuring voice in poetry written by second language learners. Written Communication, 32(1), 66-86.

Hirvela, A. (1996). Reader-response theory and ELT. ELT Journal, 50(2), 127-134. 
Isaac, A. (2002). Opening up literary cloze. Language and Education, 16(1), 18-36.

Jean, G. (1996). La poesía en la escuela (hacia una escuela de la poesía). Trans. Ana Garralón and Francisco Lapuente. Madrid: Ediciones de la Torre.

Kirchhoff, P. (2016). Is there a hidden canon of English literature in German secondary schools? In F. Klippel (Ed.), Teaching Languages-Sprachen Lehren (pp. 229-248). Münster: Waxmann.

Kormos, J. \& Csizer, C. (2008). Age-related differences in the motivation of learning English as a foreign language: Attitudes, selves and motivated learning behaviour. Language Learning, 58(2), 327-355.

Lazar, G. (1990). Using poetry with the EFL/ESL learner. Modern English Teacher, 17(3), 3-9.

Lazar, G. (2009). Literature and language teaching: A guide for teachers and trainers. Cambridge: Cambridge University Press.

Lima, C. (2010). Selecting literary texts for language learning. Journal of NELTA, 15(12), 110-114.

Maley, A. \& Duff, A. (1989). The inward ear: Poetry in the language classroom. Cambridge: Cambridge University Press.

Martin, I. (2000). Theoretical, practical and didactic reasons for using contemporary British poetry in the ELT classroom. IATEFL Literature and Cultural Studies Special Interest Group Newsletter, 19, 3-15.

McKay, S. L. (2014). Literature as content for EFL. In M. Celce-Murcia (Ed.), Teaching English as second or foreign language (pp. 319-332). Boston: Heinle \& Heinle.

Paran, A. (2008). The role of literature in instructed foreign language learning and teaching: An evidence-based survey. Language Teaching, 41(4), 465-496.

Skela, J. (2014). The quest for literature in EFL textbooks. ELOPE, 11(1), 113-136.

Vural, H. (2013). Use of literature to enhance motivation in ELT classes. Mevlana International Journal of Education, 3(4), 15-23.

Yimwilai, S. (2015). An integrated approach to teaching literature in an EFL classroom. English Language Teaching, 8(2), 14-21.

Xerri, D. \& Xerri Agius, S. (2015). Galvanizing empathy through poetry. English Journal, 104 (4), 71-76. 


\section{ANNEX}

\section{Number and percentage of comments per item and dimension}

\begin{tabular}{|c|c|c|c|}
\hline $\begin{array}{c}\text { Dimensions and items within } \\
\text { dimensions }\end{array}$ & $\begin{array}{c}\text { Positive } \\
\text { comments } \\
\text { (number and \%) }\end{array}$ & $\begin{array}{c}\text { Negative } \\
\text { comments } \\
\text { (number and \%) }\end{array}$ & $\begin{array}{c}\text { Total } \\
\text { comments } \\
\text { (number and } \\
\% \text { ) }\end{array}$ \\
\hline Linguistic dimension & $94(53.10)$ & $14(7.9)$ & $108(61.01)$ \\
\hline 1. Reading & $18(10.16)$ & $5(2.82)$ & $23(12.99)$ \\
\hline 2. Writing & $4(2.25)$ & $2(1.12)$ & $6(3.38)$ \\
\hline 3. Speaking & $8(4.51)$ & $5(2.82)$ & $13(7.34)$ \\
\hline 4. Listening & $5(2.82)$ & 0 & $5(2.82)$ \\
\hline 5. Pronunciation & $21(11.86)$ & $2(1.12)$ & $23(12.99)$ \\
\hline 6. Grammar acquisition & $13(7.34)$ & 0 & $13(7.34)$ \\
\hline 7. Vocabulary acquisition & $25(14.12)$ & 0 & $25(14.12)$ \\
\hline Intercultural dimension & 0 & $7(3.95)$ & $7(3.95)$ \\
\hline $\begin{array}{l}\text { 8. Specificities of English-speaking } \\
\text { cultures }\end{array}$ & 0 & 0 & 0 \\
\hline 9. Knowledge of L2 culture & 0 & $3(1.69)$ & $3(1.69)$ \\
\hline 10. Intercultural knowledge & 0 & $4(2.25)$ & $4(2.25)$ \\
\hline Motivation dimension & 0 & $7(3.95)$ & $7(3.95)$ \\
\hline 11. Authenticity & $8(4.51)$ & $3(1.69)$ & $11(6.21)$ \\
\hline 12. Conciseness & $7(3.95)$ & $2(1.12)$ & $9(5.08)$ \\
\hline 13. Non-triviality & 0 & $5(2.82)$ & $5(2.82)$ \\
\hline 14. Expressing one's opinions & $5(2.82)$ & $2(1.12)$ & $7(3.95)$ \\
\hline 15. Empathy towards others & $3(1.69)$ & $3(1.69)$ & $6(3.38)$ \\
\hline 16. Self-discovery & $5(2.82)$ & $3(1.69)$ & $8(4.51)$ \\
\hline 17. Values & 0 & $1(.56)$ & $1(.56)$ \\
\hline 18. Beauty & $10(5.64)$ & $5(2.82)$ & $15(8.47)$ \\
\hline
\end{tabular}

